\section{Risk management in clinical practice. Part 6a. Identifying and avoiding medico-legal risks in complete denture prosthetics}

\author{
J. F. McCord ${ }^{1}$
}

VERIFIABLE CPD PAPER
IN BRIEF
- Patients need to be advised of the considerable changes that will take place to their mouth following extractions.
- Immediate dentures will not be a perfect fit and as they become more unretentive, will require relining.
Replacement complete dentures are challenging to provide predictably and clinicians need to be mindful of such features as flabby ridges, balanced occlusion and posterior tooth form/size.

The provision of complete dentures is often perceived as a clinical 'black art' as it relies on a blend of clinical skill, scientific evidence and no little artistic interpretation. Coupled to this is a heavy reliance on patient ability to control their dentures in a muscular environment while, hopefully, coping with the various oral functions in addition to appearance. This article deals with the potential problem areas in the provision of complete dentures, reinforcing the importance of practitioners obtaining appropriate informed consent and of maintaining clinical knowledge and skills.

\section{INTRODUCTION}

On graduation, medical and, increasingly, dental graduates stand and agree to abide by the principles of an updated Hippocratic Oath. In essence, this places a moral responsibility on the clinician to embrace a lifelong responsibility to patients, dentistry and to the community.

\section{RISK MANAGEMENT IN CLINICAL PRACTICE \\ 1. Introduction \\ 2. Getting to 'yes' - the matter of consent \\ 3. Crowns and bridges \\ 4. Endodontics \\ 5. Ethical considerations for dental enhancement procedures \\ 6a. Identifying and avoiding medico-legal risks in complete denture prosthetics \\ 6b. Identifying and avoiding medico-legal risks in removable dentures \\ 7. Dento-legal aspects of orthodontic practice \\ 8. Temporomandibular disorders \\ 9. Dental implants \\ 10. Periodontology \\ 11. Oral surgery}

'Professor of Restorative Dentistry, Glasgow Dental Hospital and School, 378 Sauchiehall Street, Glasgow, G2 3JZ

Correspondence to: Professor Fraser McCord

Email: fraser.mccord@sky.com

\section{Refereed Paper}

Accepted 20 October 2009

DOI: $10.1038 /$ sj.bdj.2010.815

${ }^{\circledR}$ British Dental Journal 2010; 209: 273-276
General dento-legal aspects of care have already been outlined in this series, and this article will address those aspects of the provision of complete dentures that are specific to this treatment regime. As an overall gauge, the ultimate criterion will be as with any other medico-dental case, namely the Bolam test (1957) which was outlined in an earlier article. ${ }^{1}$

Before outlining the several stages of complete dentures, it is worth stressing that, with reference to the Bolam test, there is a complicating factor in the determination of a gold standard when considering definite guidelines in relation to complete dentures. Unlike the provision of a fixed restoration which has easily defined criteria such as marginal fit, occlusal acceptability and aesthetics, complete dentures require an essential component for success that cannot be guaranteed or even quantified. This factor is patient compliance, which includes neuro-muscular control plus an acceptance of the edentulous state.

A reasonable comparison is the analogy of riding a bicycle: some people can cycle with ease, some with difficulty but some are incapable of mastering the neuromuscular coordination required to cycle - similarly, some patients are unable to master the control of well-fitting, wellmade dentures.

The first step in the construction of complete dentures is critical in determining the chances of success, irrespective of the form of treatment, and this is predicated by good medical and dental history taking, the medico-legal implications of which have been covered in previous articles in this series. The second component of this is to assess the intra-oral status of the patient and their dentures and this is comprehensively covered in standard prosthodontic textbooks. Where treatment modalities are to be considered, and for reasons of simplicity, complete denture treatment will be divided into two forms of treatment, namely immediate complete dentures and replacement complete dentures.

\section{IMMEDIATE DENTURES}

The dento-legal aspects of this treatment form are potentially quite considerable and possibly overlooked, despite the documented research available on postextraction changes, which may be intraoral and extra-oral. Although the number of patients being rendered edentulous is smaller than it was 30 years ago, there are still patients who are being rendered edentulous.

As part of informed consent, therefore, such patients need to be aware of the sequelae of tooth extraction leading to edentulousness. These are listed in Table 1, together with the relevant references. In addition, the clinician should also be aware that there may be psychological sequelae which are not always obvious and not always predictable.

While there is no certainty in who will experience greatest resorption, there 


\begin{tabular}{|c|c|c|}
\hline Result & Clinical implication & Reference \\
\hline Maxilla reduces in size & $\begin{array}{l}\text { Loss of lip support } \\
\text { Potential to create crossbite } \\
\text { Maximum resorption reached at } 3 \text { months }\end{array}$ & Watt \& Likeman, $1974^{9}$ \\
\hline $\begin{array}{l}\text { Differential loss in } \\
\text { maxilla and mandible }\end{array}$ & $\begin{array}{l}\text { Relatively greater loss of bone in anterior mandible } \\
\text { compared to the maxilla }(4: 1)\end{array}$ & $\begin{array}{l}\text { Carlsson } \& \\
\text { Persson, } 1967^{10}\end{array}$ \\
\hline $\begin{array}{l}\text { Continuous resorption } \\
\text { of residual ridges (RRR) }\end{array}$ & $\begin{array}{l}\text { Go from a rounded (Order 1) ridge to a flat (Order } \\
5 \text { or } 6 \text { ) ridge } \\
\text { This will most likely reduce the support and stability } \\
\text { components of the denture bearing areas } \\
\text { Considerable individual variation }\end{array}$ & Atwood, $1971^{11}$ \\
\hline $\begin{array}{l}\text { Other associated } \\
\text { changes in profile }\end{array}$ & $\begin{array}{l}\text { Loss of anterior facial height } \\
\text { Pseudo-class III appearance may result } \\
\text { More bone loss in patients with a } 90^{\circ} \\
\text { mandibular angle }\end{array}$ & Tallgren, $2003^{12}$ \\
\hline $\begin{array}{l}\text { Bone retention effect } \\
\text { of overdentures }\end{array}$ & $\begin{array}{l}\text { If roots are retained (eg mandibular canines) up to } \\
\times 6 \text { bone loss may be avoided }\end{array}$ & Crum \&t Rooney, $1978^{13}$ \\
\hline Psychological changes & $\begin{array}{l}\text { Not easy to predict - perhaps indicating the need } \\
\text { for a screening test }\end{array}$ & Smith \& McCord, $2004^{14}$ \\
\hline
\end{tabular}

is clear guidance that patients with $90^{\circ}$ mandibular angles, those with prominent masseter muscles and those who may have suffered from periodontal bone loss are likely to experience more problems of bone loss, in addition to those patients suffering from or likely to experience osteoporosis. To this must be added those patients with naturally high muscle attachments; such a condition makes little difference in a dentate patient but in an edentulous patient, muscle attachments on the ridge crest or near to the crest will render conventional denture wearing impossible owing to an intrinsic failure of stability (Fig. 1). All of these features, therefore, are essential aspects of pre-extraction assessment and are important factors of which the patient must be aware before consenting to exodontia in general, and being rendered edentulous in particular.

A logical extension to this argument is that patients also need to be informed of the likelihood that immediate complete dentures are unlikely to be a perfect 'fit' on insertion and that immediate dentures will become more unretentive and probably more unstable with time. To correct this, immediate dentures may require to be relined/rebased within 4-6 weeks and replacement dentures will be indicated 3-6 months post-extraction (clearly there are exceptions to this but nevertheless, such a scenario should be explained to these problems (eg the support problem of be considered, dependant on the patient's medical status a flabby anterior maxillary ridge) often overlap into other areas (eg stability). To simplify matters, these areas are listed in Table 2. This simplified list nevertheless does cover what a 'reasonable' clinician should assess, as the treatment options open to the patient are predicated on the diagnosis.

Potential treatment options for edentulous patients are:

1. Do nothing

2. Rebase or reline the current dentures.

Care does have to be taken here,

as unless the treatment option is sound, the dentures, on return top the patient, are never the same as before rebasing/relining and thus if there is no improvement, then the patient may well be no better off and this may lead to frustration which may lead to litigation

3. Transitional dentures (including pivots). There are times when a patient has worn dentures for a long (perhaps too long) period of time with resultant wear of the occlusal surfaces. Two main problems arise here. The first is an inability of the patient to provide a reproducible retruded contact position (RCP) with the potential for many retrial visits, while the other is the fact, which must be realised, that a replacement denture may well result in a noticeable alteration to the appearance of the

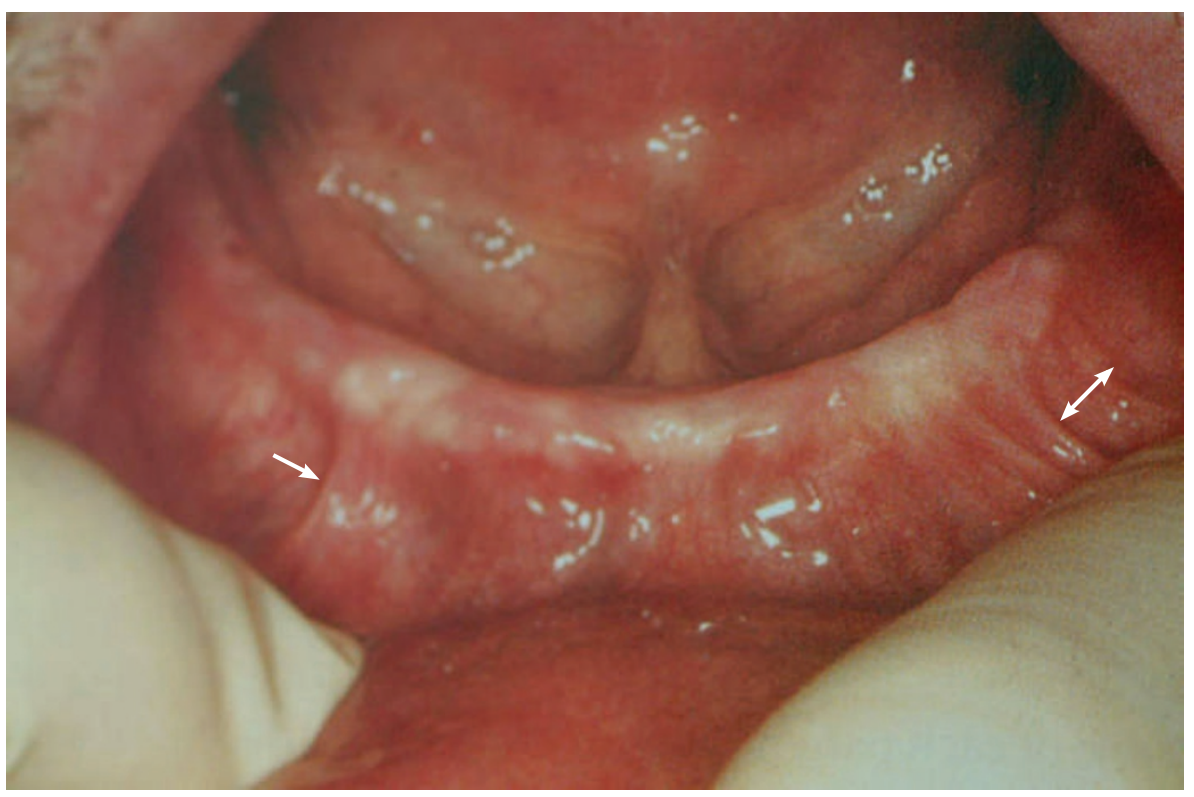

Fig. 1 Although the edentulous ridge looks favourable here, the presence of muscle attachments (arrowed) which approximate to the ridge crest will mean that a (mandibular) denture will be severely compromised and that the possibility of pre-prosthetic surgery should 


\begin{tabular}{|c|c|}
\hline Category & Descriptors \\
\hline Support & $\begin{array}{l}\text { This is reflected in the nature of the denture-bearing tissues and their ability to } \\
\text { withstand (occlusal) loads moving the dentures towards the tissues }{ }^{15}\end{array}$ \\
\hline Retention & $\begin{array}{l}\text { This is the property of the dentures to resist movement of the dentures away from } \\
\text { the tissues }{ }^{16}\end{array}$ \\
\hline Stability & $\begin{array}{l}\text { This is a paradigm of muscle balance, occlusal balance and the patient's } \\
\text { neuro-muscular control }{ }^{2,17}\end{array}$ \\
\hline Appearance & $\begin{array}{l}\text { This may involve the teeth, the denture base, the OVD and the overall form of } \\
\text { the dentures }\end{array}$ \\
\hline Miscellaneous & $\begin{array}{l}\text { This could include perceived alterations of taste, burning mouth, denture stomatitis } \\
\text { or other factors not directly attributable to the dentures }\end{array}$ \\
\hline
\end{tabular}

patient. This is perhaps most ideally treated via transitional dentures and pivots to allow the patient to stabilise her/his occlusion and also to permit a gradual alteration to the appearance of the patient ${ }^{2}$

4. Replication of the existing dentures (also termed replica or copy dentures)

5. Replacement dentures using a conventional technique

6. A conventional maxillary complete denture opposed by an implantstabilised mandibular complete denture

7. Implant stabilised maxillary and mandibular complete dentures

8. Placement of, say, six implants in each jaw and replacement of missing teeth with fixed prostheses

9. Refer the patient.

All of these options should in theory be offered to the patient although there may be good reasons, medically, psychologically or financially, which will influence which option is most appropriate for a patient, in addition to clinical and technological experience by the dental team. In addition to these options, the following factors should be kept in mind given evidence recently presented, some of which was based on randomised controlled clinical trials.

\section{Impression techniques}

Most denture schools in the UK advocate the use of the recording of primary impressions in stock trays and the recording of definite impressions in customised or 'special' trays for conventional replacement dentures. Equally, most dental schools in the UK also teach a replica or 'copy' denture technique.

There is a good degree of clinical freedom for clinicians to use a wide variety of techniques and this is reflected in the guides to standards in prosthetic dentistry published by the British Society for the Study of Prosthodontics. ${ }^{3}$ There is evidence to suggest, however, that patients with flat mandibular ridges covered with atrophic mucosa would obtain most benefit if a non-hydrophilic impression material was used using a mucodisplacive technique. ${ }^{4}$ Further, although replica techniques have considerable merit, clinicians should be aware of the fact that none of the currently used techniques caters for those support problems (eg flabby anterior maxillary ridge) where selected pressure techniques may be advisable.

Consideration of the above should always be given at the first and second clinical visits as, on the basis of the above findings, the outcome of replacement denture treatment may be influenced by the nature of the impression material used to record the definitive impressions.

\section{The nature of the occlusion}

One consequence of the diminution in the number of complete dentures prescribed by undergraduates in dental schools, allied to a marked reduction in the teaching of prosthodontics, ${ }^{5}$ is that currently, graduating dental students do so at a clinical and theoretical disadvantage to those of 10 to 20 years ago. Two of the subjects which have been reduced in number of hours taught are the teaching of dental technology and associated theory of occlusal schemes for complete dentures. Although these two aspects occupy a much smaller proportion of the undergraduate dental curriculum than hitherto, nevertheless the basic criterion for acceptability of replacement complete dentures remains unchanged, and this is that complete dentures should exhibit balanced occlusion in retruded contact position; in simple terms, the posterior teeth (canines to last teeth in the arch) should have bilateral simultaneous contacts. All patients receiving complete dentures ought therefore to be given these dentures with balanced occlusion to satisfy basic denture stability. Failure to achieve this fails to satisfy the basic principles taught in UK dental schools and therefore would be tantamount to failing the Bolam test.

Some patients, however, tend to have non-vertical but ruminatory mandibular movements and in the interests of occlusal stability, it is recommended that they be provided with dentures set up to balanced articulation, ie the dynamic, sliding contact of the denture teeth against the maxillary denture teeth in all (closed) mandibular movements. While non-specialists would not be expected to provide dentures to this standard, it could be argued that they should be able to diagnose the requirement of a patient to be provided with dentures with balanced articulation. This may be determined by offering the patient a biscuit and watching how he/she eats the biscuit; if the patient bites up and down only, balanced occlusion would suffice, whereas lateral/ruminatory movements will require balanced articulation.

\section{The nature of the posterior tooth form selected}

While not all patients require balanced articulation, those who do will require that posterior teeth are selected appropriately. This means that although the patient may have an atrophic mandibular ridge, teeth with cusps are required as it is impossible to achieve balanced articulation without cusps..$^{6,7}$ A recent randomised controlled trial of posterior tooth forms ${ }^{8}$ indicated that patients with atrophic ridges reported less satisfaction when flatcusped teeth were used compared to teeth with cusps.

This is especially important in patients being provided with implant-stabilised mandibular complete dentures. In this case, the improved stability of the mandibular denture may de-stabilise a complete maxillary denture if balanced articulation is not provided in a patient who requires this occlusal function. 


\section{Maintenance}

Mention was made in the section on immediate dentures of the need to inform the patient of post-extraction changes and the very likely need for rebase/reline procedures. As residual ridge resorption is continuous and irrevocable, all complete denture wearers must be informed of this and the fact that maintenance of one form or another will be required for the dentures and/or soft tissues. This is also true for implant-stabilised prostheses where, in addition to resorptive changes of up to 19\% by volume distal to implants, maintenance is to be expected on the precision attachments linking the denture to the stud/bar attachments. All such maintenance will have a cost implication directly or indirectly to the patient, and he/she should be made aware of the potential for maintenance.

\section{SUMMARY}

At a time when those who are edentulous are becoming more problematic to treat, undergraduate dental students are receiving less tuition in complete denture prosthodontics, either replacement or immediate. Nevertheless, it is clear that there are basic principles which need to be adhered to in order to gain informed consent and there are clear results from a small number of randomised controlled trials that give clinical guidelines on how more optimal results may be achieved. Both these principles and guidelines need to be followed if lack of success coupled to litigation is to be avoided.

1. D'Cruz L. Risk management in clinical practice. Part 2. Getting to 'yes' - the matter of consent. Br Dent J 2010; 209: 69-72.

2. McCord J F, Smith P W, Grey N J A. Treatment of edentulous patients. London: Churchill Livingstone, 2004

3. British Society for the Study of Prosthetic Dentistry. Guides to standards in prosthetic dentistry. London: Quintessence Publishing Co. Ltd, 1996.

4. McCord J F, McNally L M, Smith P W, Grey N J A. Does the nature of the definitive impression material influence the outcome of (mandibular) complete dentures? Eur J Prosthodont Restor Dent 2005: 13: 105-108.

5. McCord F. Understanding prosthodontics - where did it all go wrong? Int Dent J 2003; 53(5 Suppl): 335-339.

6. Lang B. Complete denture occlusion. Dent Clin
North Am 1996; 40: 85-101.

7. Lang B, Razzoog M E. Lingualized integration: tooth molds and an occlusal scheme for edentulous implant patients. Implant Dent 1992; 1: 204-211.

8. Sutton A F, McCord J F. A randomized clinical trial comparing anatomic, lingualized, and zero-degree posterior occlusal forms for complete dentures. J Prosthet Dent 2007; 97: 292-298.

9. Watt D M, Likeman P R. Morphological changes in the maxillary denture bearing area following the extraction of teeth. Br Dent J 1974: 136: 225-235.

10. Carlsson G E, Persson G. Morphological changes in the mandible after extraction and the wearing of dentures. Odontol Revy 1967; 18: 27-54.

11. Atwood D A. Reduction of residual ridges: a major oral disease entity. J Prosthet Dent 1971; 26: $266-279$.

12. Tallgren $\mathrm{A}$. The continuing reduction of the residual ridges in complete denture wearers: a mixed longitudinal study covering 25 years. 1972. J Prosthet Dent 2003; 89: 427-435.

13. Crum R J, Rooney G E Jr. Alveolar bone loss in overdentures: a 5-year study. J Prosthet Dent 1978; 40: 610-613.

14. Smith P W, McCord J F. What do patients expect from complete dentures? J Dent 2004; 32: 3-7.

15. Jacobson TE, Krol A J. A contemporary review of the factors involved in complete denture retention, stability and support. Part III: support. J Prosthet Dent 1983; 49: 306-313.

16. Jacobson TE, Krol A J. A contemporary review of the factors involved in complete denture retention, stability and support. Part I: retention. J Prosthet Dent 1983; 49: 5-15.

17. Jacobson TE, Krol A J. A contemporary review of the factors involved in complete denture retention, stability and support. Part II: stability. J Prosthet Dent 1983; 49: 165-172. 